Journal of Animal and Veterinary Advances 11 (2): 281-283, 2012

ISSN: $1680-5593$

(C) Medwell Journals, 2012

\title{
Morphologic Pattern of the Myenteric Plexus in Abomasum of One-Humped Camel (Camelus dromedarius) During Prenatal and Postnatal Development
}

\author{
E. Salimi Naghani \\ Department of Veterinary Anatomy, Sanandaj Branch, Islamic Azad University, Sanandaj, Iran
}

\begin{abstract}
The aim of this study was to examine morphological changes of myenteric plexus in abomasum of one-humped camel (Camelus dromedarius) during prenatal and post natal development. The researchers studied preparation of myenteric plexus in one-humped camel from 190 days of gestation to adulthood. Three regions of abomasum preparations of the myenteric plexus were stained $\mathrm{AChE}$ histochemistry in six camels from six different age groups. The axonal diameter, distance between ganglia, neuronal cell size and neuronal nucleus size were measured with the aid of light micrograph and Image J program. The meshwork expands with increasing age that the axonal diameter and inter ganglionic distance increasing with age in myenteric plexus of abomasums in camels, significantly $(\mathrm{p}<0.05)$ and neuronal cell size and neuronal nucleus size of enteric neurons also increased with age but was not statistically significant. The researchers found for the first time that the axonal thickness in myenteric plexus striking changes during the 1st 12 weeks of life in camels.
\end{abstract}

Key words: Myenteric plexus, enteric neurons, prenatal and postnatal development, camels, image, exoned diameter

\section{INTRODUCTION}

One of the most developed ganglionated plexuses of the abomasum is the myenteric plexus (Auerbach's plexus) located between the inner circular layer and outer longitudinal layer of the tunica muscularis.

The wall of the gastrointestinal tract presents extensive plexuses of nerve fibers and neuronal cell bodies responsible for the modulation of the rhythmic gastrointestinal peristaltic activities, among other functions reflecting the absence of CNS control.

Aspects of the enteric nervous system organization and in particular, the shape, neurochemistry and the projection of anally and orally projection neurons of the intestine have been determined in several species but primarily in small mammals such as the guinea pig (Brookes and Costa, 1990; Furness, 2006), the mouse (Sang et al., 1997) or in man (Wattchow et al., 1997; Porter et al., 1997, 2002).

Similar studies are rare in large mammals such as cattle (Pfannkuche et al., 2002, 2004) that they were related to the Enteric Nervous System (ENS) of the forestomach and abomasum.

The study founded that the myenteric plexus is immature at birth and the process of functional maturity of the abomasum in one-humped camel progresses after birth. This study tried to determine the quantity and various morphologic features of the maturity process of the myenteric plexus in abomasum of one-humped camel during prenatal and postnatal periods.

\section{MATERIALS AND METHODS}

The abomasum of one-humped camel preparation of the myenteric plexus were stained using $\mathrm{AChE}$ histochemistry in six camels from six differentage groups. The specimens were taken from gestational age days 190 (mid-period of gestation in camels), 280 days, newborn, 4 weeks old, 12 weeks old and adult camels that were $>2$ years and were collected from slaughter houses of semi-desert provinces of Iran. The specimens were taken from the cardiac, fundic and pyloric regions of the abomasum.

The specimens were taken using microsurgical scissors and a dissection microscope. The mucosa was removed by scraping it off the submucosal layer. This was sufficient in exposing the outer submucosal plexus and myenteric plexus in 190 and 280 days gestation specimens. In other specimens, the circular muscle fibers were peeled off one by one to expose the myenteric plexus. Staining for AChE was based on the method of Karnovsky and Roots (1964).

The images of the light microscope were taken at $100 \mathrm{x}$ magnification of the myenteric meshwork. The axon diameter, distance between midpoints of adjacent ganglia, 
neuronal size, neuronal nucleus size were measured and tabulated in excel spreadsheet. The neuronal size and neuronal nucleus size were calculated from the micrographs taken at $100 \mathrm{x}$ magnification. As for the axonal diameter, a minimum of five primary axons at their midpoint were measured per specimen. Statistical significance was performed using one-way ANOVA test. Significance was accepted at $\mathrm{p}<0.05$.

\section{RESULTS AND DISCUSSION}

Morphological features such as axonal diameter, interganglionic distance, neuronal cell size and neuronal nucleus size were measured in the dromedary. The study found these factors increased gradually with the advance of age in the myenteric plexus of abomasum and so, the results from the three regions of abomasum (cardiac, fundic and pyloric) were pooled and the meshwork of myenteric plexus was the same in all regions of abomasum. Neither the neuronal cell size nor nucleus size of the myenteric neurons were significantly increased. Only the axonal diameter and the distance between the ganglia in the age 4 and 12 weeks postnatal were significantly increased (Table 1). The meshwork of the abomasum's myenteric plexus in the one-humped camel became wider with advance of age (Fig. 1). The present results demonstrated that there is an obvious change in the morphological pattern of the myenteric plexus as well as in the axonal diameter, distance between ganglia, nuclei size and cells size during 12 weeks old in the camel abomasum. The present observation confirmed the continuous development of the myenteric plexus of the one-humped camel abomasum with the advance of age. The myenteric plexus is well formed at mid-gestation and continues maturity until 12 weeks. Most researchers have concentrated on the changes in neuronal cell correlated with age to determine the process of maturation within the enteric nervous system (Gabella, 1971; Belai et al., 1995). The study found that the distance between the ganglia increased with age beyond 4 weeks of gestation statistically.

The increased diameter of the abomasum was similarly, the axon diameter too was observed to increase sharply beyond 4 weeks of age. Concerning the effects of malnutrition on enteric neuron morphological characteristics, it has been a long standing view that the number of myenteric plexus structures is largely dependent on the diet and that protein deprivation alters their histological features (Santer and Conboy, 1990). Although, a postnatal mitotic has been noticed (Gabella, 1989) the number of neurons decreased both in aged animals and in humans (Belai et al., 1995; Doxey et al., 1995; Gabella, 1989; Gomes et al., 1997; Karaosmanoglu et al., 1996; Santer, 1994; Santer and

Table1: Mean value \pm SE of in various stages in prenatal and postnatal development of one-humped camel studied

\begin{tabular}{|c|c|c|c|c|c|c|}
\hline Various stages & 190 days & 280 days & Newbom & 4 weeks old & 12 weeks old & Adult \\
\hline Axonal diameter & $0.029 \pm 0.001$ & $0.043 \pm 0.001$ & $0.0442 \pm 0.002$ & $0.0504 \pm 0.001$ & $0.0922 \pm 0.002$ & $0.121 \pm 0.001$ \\
\hline Distance between ganglia $(\mu \mathrm{m})$ & $0.088 \pm 0.004$ & $0.287 \pm 0.023$ & $0.2900 \pm 0.010$ & $0.2810 \pm 0.032$ & $0.8190 \pm 0.026$ & $0.712 \pm 0.015$ \\
\hline Nucleus size $\left(\mu \mathrm{m}^{2}\right)$ & $39.100 \pm 1.340$ & $51.320 \pm 3.650$ & $77.6400 \pm 4.230$ & $76.1000 \pm 3.650$ & $98.2300 \pm 2.340$ & $109.450 \pm 3.570$ \\
\hline Cell size $\left(\mu m^{2}\right)$ & $89.820 \pm 3.560$ & $139.320 \pm 4.700$ & $240.5300 \pm 6.870$ & $243.3000 \pm 3.650$ & $402.4500 \pm 4.560$ & $490.300 \pm 4.450$ \\
\hline
\end{tabular}
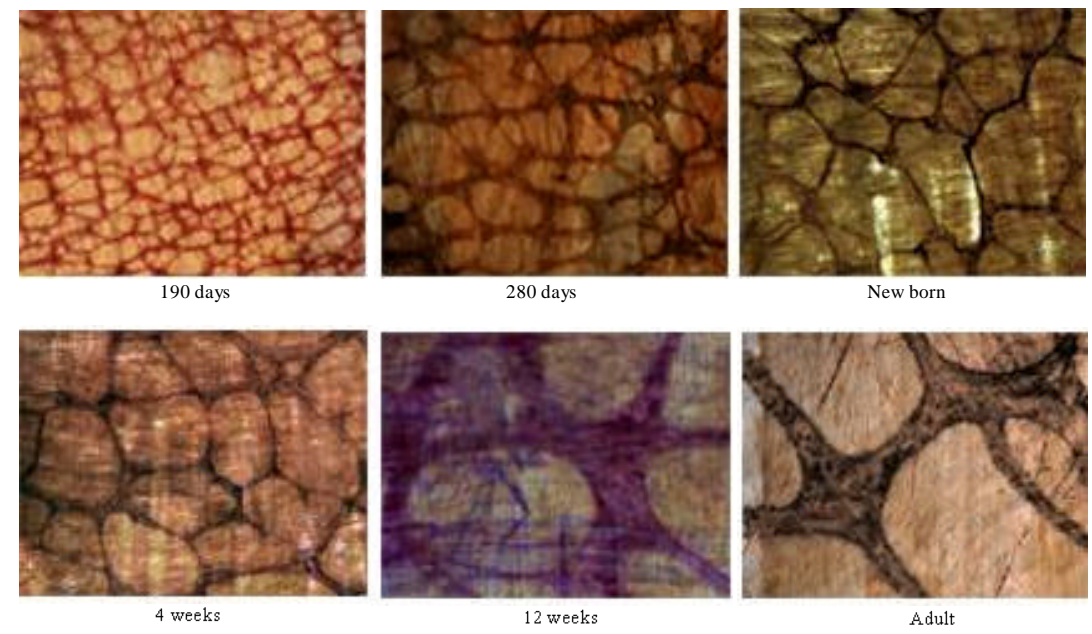

Fig. 1: Photomicrograph of the three regions of abomasum from the six different age groups in the one-humed camel. AChE stain $100 \mathrm{x}$ 
Baker, 1988). The results of this demonstrated that the axon diameter, distance between ganglia, nucleus size and cell size increases during the 12 weeks postnatal development period. This study showed for the first time that the axon thickness in the enteric myenteric plexus undergoes striking changes during the 1 st 12 weeks of life in the one-humped camel calves.

\section{CONCLUSION}

This study showed significant increase in the meshwork of nerve fibres after birth which may indicate the abomasum adaptation to its new role. Rializing the age-related development of the muscularis innervation allows one to contemplate the possibility of influencing its course during early postnatal period. This also has important implications in approaching the functional gastric obstruction in premature calves.

\section{REFERENCES}

Belai, A., S. Cooper and G. Burnstock, 1995. Effect of age on NADPH-diaphorase-containing myenteric neurons of rat ileum and proximal colon. Cell Tissue Res., 279: 379-383.

Brookes, S.J. and M. Costa, 1990. Identification of enteric motor neurons which innervate the circular muscle of the guinea pig small intestine. Neurosci. Lett., 118: $227-230$.

Doxey, D.L., G.T. Pearson, E.M. Milne, J.S. Gilmour and H.K. Chisholm, 1995. The equine enteric nervous system-neuron characterization and distribution in adults and juveniles. Vet. Res. Commun., 19: 433-449.

Furness, J.B., 2006. The Enteric Nervous System. Blackwell Publishing, Oxford, ISBN: 9781405133760 , Pages: 274.

Gabella, G., 1971. Neuron size and number in Myenteric plexus of the newborn and adult rat. J. Anat., 109: 81-95.

Gabella, G., 1989. Fall in the number of Myenteric neurons in aging guinea-pigs. Gastroenterology, 96: 1487-1493.

Gomes, O.A., R.R. de Souza and E.A. Liberti, 1997. A preliminary investigation of the effects of aging on the nerve cell number in the myenteric ganglia of the human colon. Gerontology, 43: 210-217.
Karaosmanoglu, T., B. Aygun, P.R. Wade and M.D. Gershon, 1996. Regional differences in the number of neurons in the Myenteric plexus of the guinea pig small intestine and colon: An evaluation of markers used to count neurons. Anat. Rec., 244: 470-480.

Karnovsky, M.J. and L. Roots, 1964. A "direct coloring" thiocholine method for cholinesterases. J. Histochem. Cytochem., 12: 219-221.

Pfannkuche, H., M. Schemann and G. Gabel, 2002. Ruminal muscle of sheep is innerved by non-polarized pathways of cholinergic and nitregic myenteric neurons. Cell Tissue Res., 309: 347-354.

Pfannkuche, H., C. Schellhorn, M. Schemann and G. Gabel, 2004. Intrinsic innervation patterns of the smooth muscle in the rumen and reticulum of lamb. J. Anat., 204: 293-299.

Porter, A.J., D.A. Wattchow, S.J. Brookes and M. Costa, 1997. The neurochemical coding and projection of circular muscle motor neurons in the human colon. Gastroentrology, 113: 1916-1923.

Porter, A.J., D.A. Wattchow, S.J.H. Brookes and M. Costa, 2002. Cholinergic and nitrergic interneurons in the Myenteric plexus of the human colon. Gut, 51: 70-75.

Sang, Q., S. Williamson and H.M. Young, 1997. Projection of chemically identified myenteric neurons of the small and large intestine of the mouse. J. Anat, 190: 209-222.

Santer, R.M. and D.M. Baker, 1988. Enteric neuron numbers and sizes in Auerbach's plexus in the small and large intestine of adult and aged rats. J. Auton. Nerv. Syst., 25: 59-67.

Santer, R.M. and V.B. Conboy, 1990. Prenatal undernutrition permanently decreases enteric neuron number and sympathetic innervation of Auerbach's plexus in the rat. J. Anat., 168: 57-62.

Santer, R.M., 1994. Survival of the population of NADPHdiaphorase stained myenteric neurons in the small intestine of aged rats. J. Autonom. Nerv. Syst., 49: 115-121.

Wattchow, D.A., A.J. Porter, S.J. Brooks and M. Costa, 1997. The polarity of neuruchemically defined myenteric neurons in the human colon. Gastroenterology, 113: 497-506. 